\title{
Effect of dietary conjugated linoleic acid (CLA) on the metabolism and reproduction of dairy cows
}

\author{
G. Esposito ${ }^{1,2 \#}$, V.A. Absalón Medina ${ }^{2}$, A. Schneider ${ }^{2,3}$, R.O. Gilbert ${ }^{4}$ \& W.R. Butler ${ }^{2}$ \\ ${ }^{1}$ Department of Production Animal Studies, Faculty of Veterinary Sciences, University of Pretoria, South Africa; \\ ${ }^{2}$ Department of Animal Science, Cornell University, Ithaca, NY, USA; \\ ${ }^{3}$ Faculty of Veterinary Sciences, Universidade Federal de Pelotas, RS, Brazil; \\ ${ }^{4}$ Department of Clinical Sciences, College of Veterinary Sciences, Cornell University, Ithaca, NY, USA.
}

(Received 30 September 2012; Accepted 14 February 2013; First published online 5 July 2013)

\begin{abstract}
Copyright resides with the authors in terms of the Creative Commons Attribution 2.5 South African Licence.
See: http://creativecommons.org/licenses/by/2.5/za/

Condition of use: The user may copy, distribute, transmit and adapt the work, but must recognise the authors and the South African Journal of Animal Science
\end{abstract}

\begin{abstract}
Rumen-protected conjugated linoleic acid (CLA) reportedly improves fertility in lactating dairy cows by reducing the postpartum interval to first ovulation and enhancing the circulating insulin-like growth factor-I (IGF-I) levels. The objectives of this study were to evaluate the blood metabolites, hormones, follicular fluid (FF) and liver for the effect of CLA supplementation (50 g top-dressed daily from 15 days pre-partum to 65 days in milk -DIM -). Pre-partum Holstein cows $(n=24)$ were assigned to two treatments: a Control and CLA group ( $\mathrm{n}=12$ cows/group). Dry matter intake (DMI) and milk production were recorded daily. At 26 DIM, ovulation was synchronized and at 34 DIM, plasma and FF were analysed for paraoxonase 1(PON) levels. Moreover plasma was analysed for IGF binding protein 2 and 3 (IGFBP). From 34 DIM, blood samples and FF from follicles $>9 \mathrm{~mm}$ were collected and analysed for estradiol, progesterone, IGF-I and lipoproteins. A liver biopsy was performed at 65 DIM and analysed for the expression of IGF-I, growth hormone receptor (GHR), pyruvate carboxylase (PC) and cytosolic phosphoenolpyruvate carboxykinase (PECK). CLA supplemented cows, compared to the control group, recorded a significant lower milk fat production, improved DMI and energy balance and recorded significant increased plasma concentrations of IGF-I, cholesterol, low density lipoprotein (LDL) and IGFBP-3 (interaction treatment $x$ DIM). The concentration of IGF-I, high density lipoprotein (HDL) and LDL tended to be higher in FF than plasma. This study confirms the positive effects of dietary CLA supplementation on the metabolism, by improving the energy intake and reducing the negative energy balance. Moreover, the improvement of plasma IGF-I levels observed in this study, coupled with a better energy balance support previous studies showing a positive effect of CLA supplementation on reproduction. However, CLA did not alter the plasma and the FF concentration of PON, nor the liver gene expression.
\end{abstract}

Keywords: Follicular fluid, liver gene expression, postpartum cows

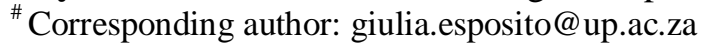

\section{Introduction}

High-yielding dairy cows are typically in a negative energy balance postpartum, because of the amount of energy required for maintenance, plus milk production exceeds the amount of energy that cows ingest. An insufficient energy supply generally results in a poor reproductive performance that is associated with a delay in the onset of the oestrous cycles postpartum (Butler \& Smith, 1989; Reist et al., 2000), low conception rates and a high rate of early embryonic deaths (Lucy, 2001). Dietary fat supplements in early lactation may benefit the reproductive outcome by improving the energy intake and reducing the extent of the negative energy balance, as well as by increasing the size of the ovulatory follicle and lifespan of the corpus luteum (Mattos et al., 2000). Furthermore, it has been shown that with CLA supplementation, the 
plasma concentration of Insulin-like growth factor-I (IGF-I) is elevated (Castaneda-Gutierrez et al., 2007). Cows with higher circulating IGF-I levels during the first 12 wk postpartum are more likely to conceive than those with lower IGF-I levels. The mechanism through which CLA increases the circulating IGF-I is unknown, but it may act through the liver growth hormone receptor (GHR). During a negative energy balance in early lactation, the liver is refractory to growth hormone (GH), resulting in low concentrations of circulating IGF-I. However, greater insulin availability restores the coupling of the GH-GHR-IGF-I axis, increasing the circulating IGF-I concentrations (Butler et al., 2003). In other studies a 50 : 50 mixture of cis9, trans-11 and trans-10, cis-12 CLA increased the insulin sensitivity in muscle (Ryder et al., 2001) and increased genes related to insulin sensitivity in Zucker diabetic rats (Inoue et al., 2006). Moreover, CLA increased the plasma lipoprotein concentrations in cattle (Trevisi et al., 2008). In vitro studies have demonstrated that high and low density lipoproteins (HDL and LDL) generally promote bovine granulosa cell viability (Bao et al., 1995) and stimulate greater progesterone and IGF-I secretions in bovine luteal cell cultures (Bao et al., 1997). The proposed anti-inflammatory effects of CLA may then protect the anti-oxidant paraoxonase1 (PON) from inactivation (Su et al., 2003). The overall goal and design of the study was thus to explore the potential actions through which dietary supplementation with CLA may improve fertility and metabolism in lactating dairy cows, by effects on the ovarian follicles and liver.

\section{Materials and Methods}

Multiparous Holstein cows $(n=24)$ at the Teaching and Research Centre of the Cornell University, USA were blocked according to parity, body weight and body condition score and were assigned, in a randomized design trial into two treatment groups: a control diet (ctl) and a CLA diet (cla) group in which a rumen-protected formulation of cis-9,trans-11 and trans-10,cis-12 isomers of the conjugated linoleic acid (50 $\mathrm{g} / \mathrm{d}$; Lutrell*Pure $($ ), providing $5 \mathrm{~g}$ of rumen protected trans-10, cis-12 CLA, was top-dressed on the total mixed ration (TMR), once daily. The supplementation was provided from 15 days before the predicted calving date, until the end of the experiment at 65 days in milk (DIM). The basal diet was a TMR formulated using the Cornell Net Carbohydrate and Protein System, to meet or exceed the nutrient requirements. Cows were fed ad libitum to allow $10 \%$ orts. At 26 DIM follicular development was synchronized with the aid of a vaginal progesterone controlled internal drug-releasing device (CIDR, InterAg, Hamilton, New Zealand) and an injection of GnRH (100 $\mu \mathrm{g}$; Cystoreline, Abbott Laboratories, North Chicago, IL), followed by an injection of PGF $2 \alpha$ one week later (25 mg; Lutalyse; Pharmaca and Upjohn). Dry matter Intake (DMI) and milk production were recorded daily. Every 10 days, composite milk samples were collected, and stored at $4{ }^{\circ} \mathrm{C}$ with a preservative (2-bromo-2nitropropane-1,3-diol: Bronolab-W II), until analysed for fat, true protein, somatic cells and lactose, as described by Bernal-Santos et al. (2003). The energy balance (EBAL) was calculated based on the equations of the NRC (2001), where net energy (NE) balance equals: [(DMI x net energy for lactation (NEL) in the diet)-BW 0.75 x 0.08) + milk energy]. From 34 DIM until 65 DIM blood samples were collected every four days from each cow, via coccygeal venipuncture, into a vacuum tube containing EDTA (100 U/mL of blood). The plasma was harvested within 20 min after collection, by centrifugation $\left(2800 \mathrm{~g}\right.$ for $15 \mathrm{~min}$ at $4{ }^{\circ} \mathrm{C}$ ) and the aliquots stored at $-20{ }^{\circ} \mathrm{C}$ for further analyses (IGF-I, cholesterol, LDL and HDL). Aspiration of the follicles with a diameter $>9 \mathrm{~mm}$ was done on 34, 42, and 50 DIM, according to the procedure described by Manik et al. (2003). Follicular fluid was centrifuged for $7 \mathrm{~min}$ at $1500 \mathrm{G}$ at $4{ }^{\circ} \mathrm{C}$. After that, the supernatant was stored at $-20^{\circ} \mathrm{C}$, until further analyses for hormones and lipoproteins. At 65 DIM, a liver sample was collected from each cow by needle biopsy, as described by Rhoads et al. (2008). Liver tissue samples were analysed for gene expression of GHR, IGF-I, pyruvate carboxylase (PC) and cytosolic phosphoenolpyruvate carboxykinase (PECK). Individual daily milk production and DMI values were transformed to weekly means before analysis and the yields for milk fat, protein and lactose content were calculated using the weekly mean for milk production. For all analyses, significance was declared at $P<0.05$ and trends at $P \leq 0.10$. Production, blood metabolites and hormones were evaluated using the ANOVA for repeated measures, with the PROC MIXED procedure (SAS, 2001). Abundance of RNA in the liver was analysed using the t-test and the Satterthwaite procedure.

\section{Results and Discussion}

Conjugated linoleic acid supplementation did not affect milk production, but decreased milk fat production $(P<0.05)$. This result was in accordance with the results shown by Castaneda-Gutierrez et al. 
(2007) and in contrast with other studies that reported modest increases of 3\% to $10 \%$ in milk yield when cows were fed similar amounts of trans-10,cis-12 isomers of CLA (Bernal-Santos et al., 2003; Mackle et al., 2003; De Veth et al., 2006). Decreased milk fat was induced by CLA supplementation, with an improved energy balance in the cows (Figure 1$)(P<0.05)$.

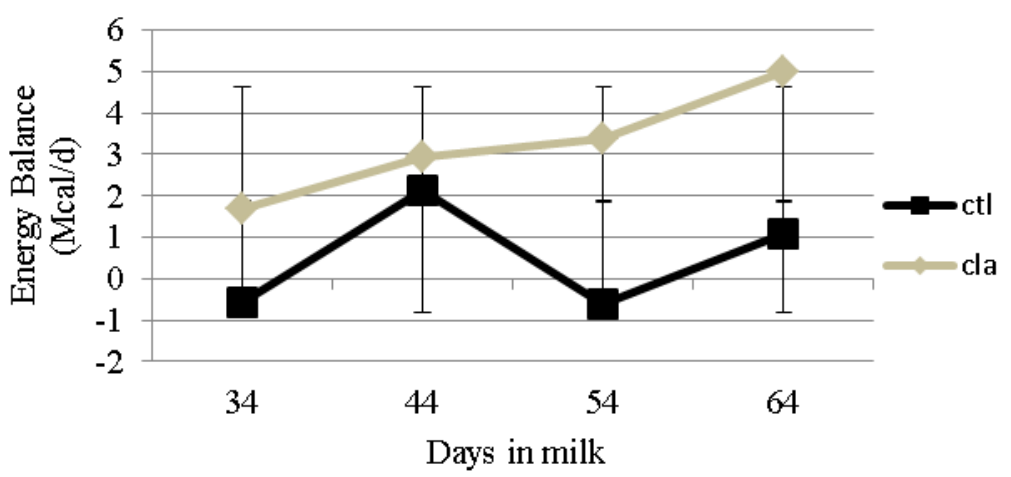

Figure 1 Least square means for energy balance in the control (ctl) and CLA (cla) groups, based on the NRC (2001).

Dietary CLA increased the plasma cholesterol and LDL concentration (Figure 2 and Figure 3) ( $P$ $<0.05$ ), suggesting a beneficial effect on the attenuation of hepatic inflammatory effects after calving. Only a positive trend was observed for plasma HDL in the CLA treated cows (interaction treatment $\mathrm{x}$ DIM) $(P$ $<0.1)$. A positive trend for HDL and LDL levels was also recorded in the follicular fluid of the cows fed CLA $(P<0.1)$. Since in vitro studies have shown that both, HDL and LDL increase granulosa cells viability and the production of progesterone and IGF-I by the luteal cells (Bao et al., 1995; 1997), results corroborate the hypothesis of a positive effect of dietary supplementation of CLA on reproduction.

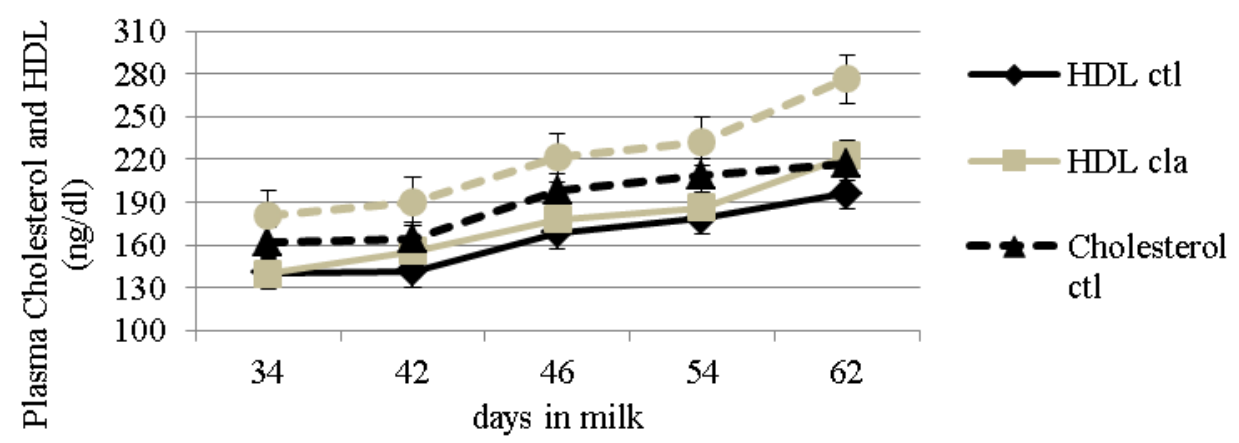

Figure 2 Least square means for plasma cholesterol and HDL in control (ctl) and CLA (cla) treated cows.

In agreement with a previous study (Castaneda-Gutierrez et al., 2007), plasma and follicular fluid IGF-I levels were higher in the CLA treated cows $(P<0.05)$ (Figures 4 and 5). Higher IGF-I levels would be expected to have a positive effect in reducing the postpartum interval to first ovulation reported in previous studies. The plasma levels of IGFBP3 were higher in cows fed CLA (treatment x DIM) $(P<0.05)$, but no differences were recorded for IGFBP2. Plasma and follicular fluid concentration of PON were similar between the groups, as well as the ratio of PON/HDL in the plasma and follicular fluid. Moreover, no differences were recorded between the two groups regarding the relative abundance of gene expression analysed in the liver. 


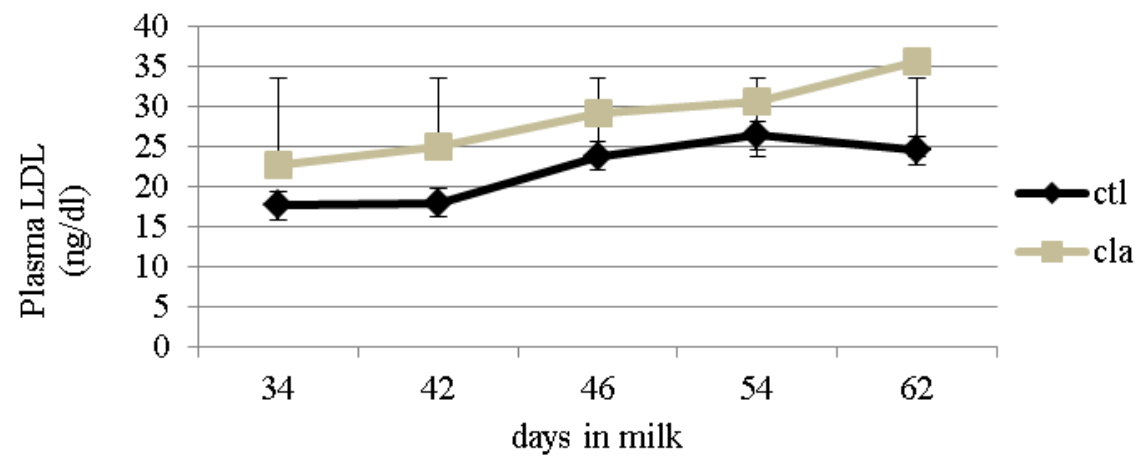

Figure 3 Least square means for plasma LDL in control (ctl) and CLA (cla) supplemented cows.

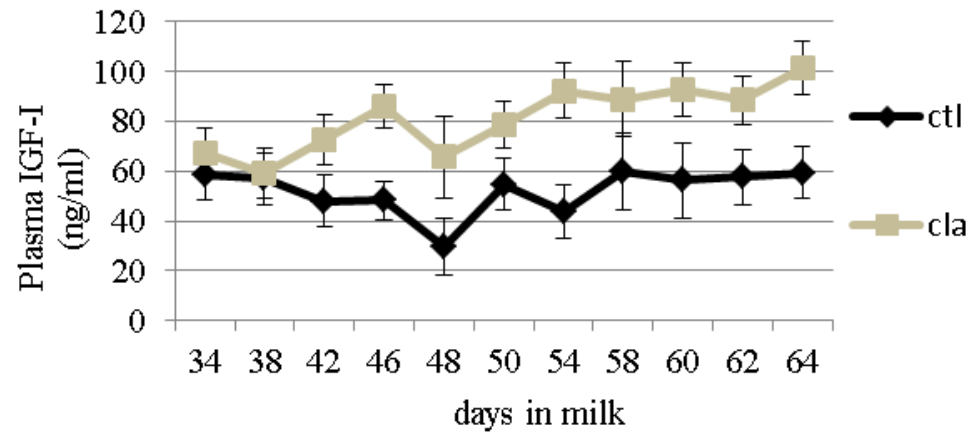

Figure 4 Least square means of plasma IGF-I levels in the CLA (cla) and Control (ctl) cows.

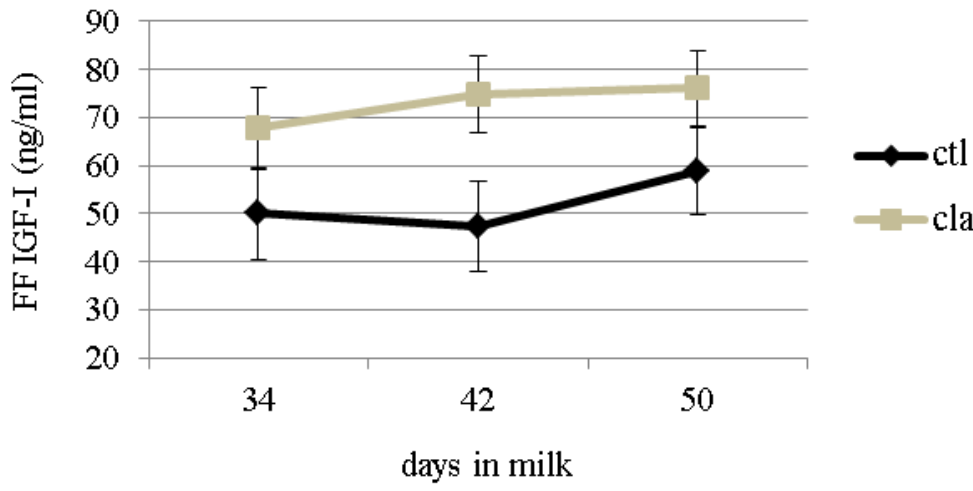

Figure 5 Least square means of follicular fluid IGF-I levels in Control (ctl) and CLA (cla) treated cows.

\section{Conclusion}

The mechanisms in potential target tissues through which CLA can improve the reproduction and metabolism in dairy cows have not been defined and still warrant further study. A higher CLA dose level may further enhance the effects on hepatic gene expression.

\section{References}

Bao, B., Thomas, M., Grifith, M., Burghart, R. \& Williams, G., 1995. Steroidogenic activity, insulin-like growth factor-I production and proliferation of Granulosa and Theca Cells obtained from dominant 
preovulatory and nonovulatory follicles during the bovine estrous cycle: Effects of low-density and high -density lipoproteins. Biol. Reprod. 53, 1271-1279.

Bao, B., Thomas, M. \& Williams, G., 1997. Regulatory roles of high-density and low density lipoproteins in cellular proliferation and secretion of progesterone and insulin-like growth factor-I by enriched cultures of bovine small and large luteal cells. J. Anim. Sci. 75, 3235.

Bernal-Santos, G., Perfield $2^{\text {nd }}$, J.W., Barbano, D.M., Bauman, D.E. \& Overton, T.R., 2003. Production responses of dairy cows to dietary supplementation with conjugated linoleic acid (CLA) during the transition period and early lactation. J. Dairy Sci. 86, 3218-3228.

Butler, S.T., Marr, A.L., Pelton, S.H., Radcliff, R.P., Lucy, M.C. \& Butler, W.R., 2003. Insulin restores GH responsiveness during lactation-induced negative energy balance in dairy cattle: Effects on expression of IGF-I and GH receptor 1A. J. Endocrinol. 176, 205-217.

Butler, W.R. \& Smith, R.D., 1989. Interrelationships between energy balance and postpartum reproductive function in dairy cattle. J. Dairy Sci. 72, 746-783.

Castenda-Gutiérrez, E., Benefield, B.C., De Veth, M.J., Santos, N.R., Gilbert, R.O., Butler, W.R. \& Bauman, D.E., 2007. Evaluation of the mechanism of action of conjuagetd linoleic acid isomers on reproduction in dairy cows. J. Dairy Sci. 90, 4253-4264.

De Vath, M.J., Castaneda-Gutiérrez, E., Dwyer, D.A., Pfeiffer, A.M., Putnam, D.E. \& Bauman, D.E., 2006. Response to conjugated linoleic acid in dairy cows differing in energy and protein status. Dairy Sci. 89, 4620-4631.

Inoue, N., Nagao, K., Wang, Y.M., Noguchi, H., Shirouchi, B. \& Yanagita, T., 2006. Dietary conjugated linoleic acid lowered tumor necrosis factor-alpha content and altered expression of genes related to lipid metabolism and insulin sensitivity in the skeletal muscle of zucker rats. J. Agric. Food. Chem. 54, 7935-7939.

Lucy, M.C., 2001. Reproductive loss in high-producing dairy cattle: Where will it end? J. Dairy Sci. 84, 1277-1293.

Mackle, T.R., Kay, J.K., Auldist, M.J., McGibbon, A.K.H., Philpott, B.A., Baumguard, L.H. \& Bauman, D.E., 2003. Effects of abomasal infusion of conjugated linoleic acid on milk fat concentration and yield from pasture-fed dairy cows. J. Dairy Sci. 86, 644-652.

Manik, R.S., Singla, S.K. \& Palta, P., 2003. Collection of oocytes through transvaginal ultrasound-guided aspiration of follicles in an Indian breed of cattle. Anim. Reprod. Sci. 76, 155-161.

Mattos, R., Staples, C.R. \& Thatcher, W.W., 2000. Effects of dietary fatty acids on reproduction in ruminants. Reprod. 5, 38.

National Research Council, 2001. Nutrient requirements of dairy cattle. $7^{\text {th }}$ rev. ed. National Academy Press, Washington D.C., USA.

Reist, M., Koller, A., Busato, A., Kupfer, U. \& Blum, J.W., 2000. First ovulation and ketone body status in the early postpartum period of dairy cows. Theriogenology 54, 658-701.

Rhoads, M.L., Meyer, J.P., Lamberson, W.R., Keisler, D.H. \& Lucy, M.C., 2008. Uterine and hepatic gene expression in relation to days postpartum, estrus and pregnancy in postpartum dairy cows. J. Dairy Sci. 91, 140-150.

Ryder, J.W., Portocarrero, C.P., Song, X.M., Cui, L., Yu, M., Combatsiaris, T., Galuska, D.E., BArbano, D.M. \& Charron, M.J., 2001. Isomer-specific antidiabetic properties of conjugated linoleic acid. Diabetes 50, 1149.

Su, N.D., Liu, X.W., Kim, M.R., Jeong, T.S. \& Sok, D.E., 2003. Protective action of CLA against oxidative inactivation of paraoxonase 1, an antioxidant enzyme. Lipids 38, 615-622. 